\title{
The In Vivo Effects of the $\mathrm{CB}_{1}$-Positive Allosteric Modulator GAT229 on Intraocular Pressure in Ocular Normotensive and Hypertensive Mice
}

\author{
Elizabeth A. Cairns, ${ }^{1}$ Anna-Maria Szczesniak, Alex J. Straiker, ${ }^{2}$ Pushkar M. Kulkarni, \\ Roger G. Pertwee, Ganesh A. Thakur, William H. Baldridge, ${ }^{5,6}$ and Melanie E.M. Kelly,
}

\begin{abstract}
Purpose: Orthosteric cannabinoid receptor $1\left(\mathrm{CB}_{1}\right)$ activation leads to decreases in intraocular pressure (IOP). However, use of orthosteric $\mathrm{CB}_{1}$ agonists chronically has several disadvantages, limiting their usefulness as clinically relevant drugs. Allosteric modulators interact with topographically distinct sites to orthosteric ligands and may be useful to circumvent some of these disadvantages. The purpose of this study was to investigate the effects of the novel $\mathrm{CB}_{1}$-positive allosteric modulator (PAM) GAT229 on IOP.

Methods: IOP was measured using rebound tonometry in anesthetized normotensive C57B1/6 mice and in a genetic model of ocular hypertension [nose, eyes, ears (nee) mice] before drug administration, and at 1, 6, and $12 \mathrm{~h}$ thereafter.

Results: In normotensive mice, topical administration of $5 \mu \mathrm{L}$ GAT229 alone at either $0.2 \%$ or $2 \%$ did not reduce IOP. However, a subthreshold dose $(0.25 \%)$ of the nonselective orthosteric $\mathrm{CB}_{1}$ agonist WIN 55,212-2, when combined with $0.2 \%$ GAT229, significantly reduced IOP compared with vehicle at 6 and $12 \mathrm{~h}$. Similarly, combination of subthreshold $\Delta^{9}$-tetrahydrocannabinol (a nonselective orthosteric $\mathrm{CB}_{1}$ agonist; $1 \mathrm{mg} / \mathrm{kg}$ ) with topical $0.2 \%$ GAT229 produced IOP lowering at $6 \mathrm{~h}$. In nee mice, administration of topical $0.2 \%$ GAT229 or $10 \mathrm{mg} / \mathrm{kg}$ GAT229 alone was sufficient to lower IOP at 6 and $12 \mathrm{~h}$, and $12 \mathrm{~h}$, respectively.

Conclusions: The $\mathrm{CB}_{1}$ PAM GAT229 reduces IOP in ocular hypertensive mice and enhanced $\mathrm{CB}_{1}$-mediated IOP reduction when combined with subthreshold $\mathrm{CB}_{1}$ orthosteric ligands in normotensive mice. Administration of $\mathrm{CB}_{1}$ PAMs may provide a novel approach to reduce IOP with fewer of the disadvantages associated with orthosteric $\mathrm{CB}_{1}$ activation.
\end{abstract}

Keywords: cannabinoids, cannabinoid receptor 1, allosteric modulator, glaucoma, intraocular pressure

\section{Introduction}

$\mathbf{G}$ LAUCOMA, THE LEADING CAUSE of irreversible blindness worldwide, is a group of optic neuropathies involving selective retinal ganglion cell (RGC) loss. ${ }^{1}$ Current therapeutic strategies for the treatment of glaucoma include management of intraocular pressure (IOP). ${ }^{2,3}$ For every $\mathrm{mmHg}$ reduction in IOP, there is a $10 \%$ reduced risk of progression of glaucomatous visual field loss. ${ }^{2}$ In the years since the initial reports of cannabis-induced IOP lowering in humans, the effects of cannabinoids have been studied extensively in the eye. ${ }^{4-6}$ Components of the endocannabinoid system (ECS) are present throughout the eye, including structures associated with both aqueous humor production and outflow, in addition to the retina. ${ }^{4,5}$ Activation of cannabinoid receptor $1\left(\mathrm{CB}_{1}\right)$, through topical, oral, and inhaled routes of administration of synthetic cannabinoids and phytocannabinoids, decreases IOP in both animal models and humans..$^{7-19}$ The mechanism of these hypotensive effects involves local actions that may affect both aqueous

\footnotetext{
${ }^{1}$ Department of Pharmacology, Dalhousie University, Halifax, Nova Scotia, Canada.

${ }^{2}$ Department of Psychological and Brain Sciences, Indiana University, Bloomington, Indiana.

${ }^{3}$ Department of Pharmaceutical Sciences School of Pharmacy, Bouvé College of Health Sciences, Northeastern University, Boston, Massachusetts.

${ }^{4}$ School of Medicine, Medical Sciences, and Nutrition, Institute of Medical Sciences, University of Aberdeen, Aberdeen, Scotland.

${ }^{5}$ Department of Medical Neuroscience, Dalhousie University, Halifax, Nova Scotia, Canada.

${ }^{6}$ Department of Ophthalmology and Visual Sciences, Dalhousie University, Halifax, Nova Scotia, Canada.
} 
humor inflow and outflow, ${ }^{20-27}$ and also appears to involve, at least in part, $\beta$ adrenergic receptors. ${ }^{28}$

Although glaucomatous RGC death has been extensively studied, ${ }^{29-34}$ to date, no drug designed specifically as an RGC neuroprotectant has successfully made it to the market. ${ }^{35-39}$ Several studies have reported that, aside from IOPlowering effects, modulation of the ECS is neuroprotective, including in some models of glaucoma. ${ }^{40-44}$ Therefore, it has been suggested that the ECS, and more specifically $\mathrm{CB}_{1}$ modulation, may be a strategy that could provide both IOPlowering properties and direct neuroprotection in glaucomatous RGC death. ${ }^{4,34,45}$

However, direct activation of $\mathrm{CB}_{1}$ via orthosteric ligands has several disadvantages, limiting the potential of $\mathrm{CB}_{1}$ as a clinically relevant druggable target. First, $\mathrm{CB}_{1}$-mediated hypotensive effects are relatively transient. For example, Hudson et al. ${ }^{28}$ found that $2 \mathrm{~h}$ after administration, the IOPlowering effect of the nonselective $\mathrm{CB}_{1} / \mathrm{CB}_{2}$ agonist WIN 55,212-2 (WIN) was no longer present. Second, repeated administration of cannabinoids can lead to desensitization of the receptor, ultimately resulting in a complete loss of effect. This was recently demonstrated by Ghosh et al., ${ }^{46}$ who showed that repeated high doses of the endocannabinoid enzyme inhibitor JZL184, which increases levels of the endocannabinoid 2-arachidonoyl glycerol (2-AG), caused tolerance in their model of inflammatory nociception. Third, systemic exposure to cannabinoids is known to cause adverse effects, including psychotropic and cardiac effects. ${ }^{47,48}$

Allosteric modulation of $\mathrm{CB}_{1}$ may be one means to enhance $\mathrm{CB}_{1}$ signaling, while minimizing disadvantages associated with direct orthosteric activation. ${ }^{49-53}$ The first $\mathrm{CB}_{1}$ allosteric modulator was described by Price et al. in $2005,{ }^{54}$ and since then, several additional allosteric modulators have been synthesized and characterized. ${ }^{52,53,55}$ These compounds have the potential to manipulate orthosteric activation of $\mathrm{CB}_{1}$, by either changing affinity to the binding site or efficacy of activation; but, unlike agonists, cannot activate the receptor on their own. ${ }^{56}$ Many of the negative side effects associated with $\mathrm{CB}_{1}$ activation, such as psychoactivity, occur when the receptor is activated at supraphysiological levels, disrupting normally tightly controlled spatial and temporal activation. ${ }^{6,57}$ Use of positive allosteric modulators (PAMs) may enable pharmacological fine-tuning of activation, enhancing receptor activity while maintaining spatial and temporal control. ${ }^{51,53,56}$ This results in an improved safety profile over direct orthosteric activation, similar to that observed with benzodiazepines acting at GABA receptors. ${ }^{58}$

As $\mathrm{CB}_{1}$ allosteric modulation is yet to be investigated as a therapeutic strategy for the treatment of glaucoma, we aimed to investigate the effects of GAT229, a recently characterized $\mathrm{CB}_{1}$ PAM, ${ }^{59}$ either alone or in combination with a $\mathrm{CB}_{1}$ orthosteric ligand, on IOP in normotensive and ocular hypertensive mice.

\section{Methods}

\section{Animal husbandry}

All experiments were performed in accordance with ethical guidelines from the Canadian Council for Animal Care and the ARVO Statement for the Use of Animals in Ophthalmic and Vision research, and were approved by Dalhousie's University Committee on Laboratory Animals. Male C57Bl/
$6 \mathrm{~J}$ and $S h 3 p x d 2 b$ heterozygous mice were obtained from Jackson Laboratory (Bar Harbor, ME). Both male and female nose, eyes, ears (nee) mutant mice were used. Nee mice were identified by mutated phenotypical morphology, as described by Mao et al., ${ }^{60}$ which included a shortened nose length and domed heads. Mice were kept in a $12 \mathrm{~h}$ light/ $12 \mathrm{~h}$ dark cycle (07:00-19:00) and were fed ad libitum.

\section{Drugs and reagents}

GAT229 was synthesized ${ }^{59,61}$ and provided by Dr. Ganesh Thakur (Northeastern University, Cambridge, MA). Topically delivered drugs [5 $\mu \mathrm{L}$, including WIN 55,212-2 (BioTechne, Abingdon, OX, United Kingdom)] were dissolved in the standard vehicle containing 2\% DMSO (Sigma-Aldrich, Oakville, ON, Canada) and 4\% Tween-20 (Sigma-Aldrich) in Tocrisolve (Bio-Techne, Minneapolis, MN). I.p. administered drugs [GAT229 and $\Delta^{9}$-tetrahydrocannabinol $\left(\Delta^{9}-\right.$ THC); Cayman Chemical, Ann Arbor, MI] were dissolved in a vehicle containing 1:1:18 ethanol, Kolliphor EL (SigmaAldrich), and saline at $1 \mathrm{mg} / \mathrm{mL}$.

\section{IOP measurements}

To reduce variability due to diurnal changes in IOP and therefore potentially obscuring any drug-mediated IOP change, ${ }^{62,63}$ all measurements were initiated at the same time each day (09:30). Anesthesia was induced in mice using 3\% isoflurane at $1 \mathrm{~L} / \mathrm{min}$ and then maintained at $1.5 \%$ throughout the recordings. Once the pedal reflex disappeared $(\sim 2 \mathrm{~min}$ after induction), 10 recordings were taken in each eye using a handheld rebound tonometer (Tonolab; Icare, Finland) calibrated to mouse. The average of 10 recordings was used for data analysis. Topical and i.p. drugs were administered immediately following the initial baseline IOP measurements, and follow-up IOP recordings were carried out 1,6 , and $12 \mathrm{~h}$ after initial administration. All IOPs are reported as the change in pressure (in $\mathrm{mmHg}$ ) from the baseline recording. Analysis using the change in IOP from baseline, rather than the absolute IOP, controlled for variability in IOP both between eyes and between animals.

\section{Data analysis}

Statistical analysis was performed using GraphPad version 6.0 (GraphPad Software, Inc., La Jolla, CA). All data are presented as mean \pm S.E.M. $T$-tests were used to compare between 2 groups. Paired $t$-tests were used to compare between eyes of the same animal. Three or more groups were compared using one-way analysis of variance with a Dunnett's post hoc test to compare between groups. A $P$ value of $<0.05$ was considered significant.

\section{Results}

\section{$C B_{1}$ allosteric modulation of IOP in normotensive mice}

To explore the effects of $\mathrm{CB}_{1}$ PAMs on normotensive mice, male $\mathrm{C} 57 \mathrm{~B} 1 / 6 \mathrm{~J}$ mice were administered either topical $0.2 \%$ or $2 \%$ GAT229 (Fig. 1A) in 1 eye, with the contralateral eye receiving vehicle. While the reduction in IOP caused by $\mathrm{CB}_{1}$ orthosteric ligands is typically very short in duration $(1-2 \mathrm{~h}){ }^{11-14,16,28,64-66}$ the time course of any 
A

FIG. 1. The $\mathrm{CB}_{1}$ PAM GAT229 alone does not reduce IOP in normotensive $\mathrm{C} 57 \mathrm{Bl} / 6 \mathrm{~J}$ mice. (A) The structure of the $\mathrm{CB}_{1}$ PAM GAT229. Given topically at either $0.2 \% \quad(n=7$, B) or $2 \%(n=4$, C), GAT229 alone does not reduce IOP in normotensive $\mathrm{C} 57 \mathrm{~B} 1 / 6$ mice 1,6 , or $12 \mathrm{~h}$ after administration. $\mathrm{CB}_{1}$, cannabinoid receptor 1; IOP, intraocular pressure; PAM, positive allosteric modulator.
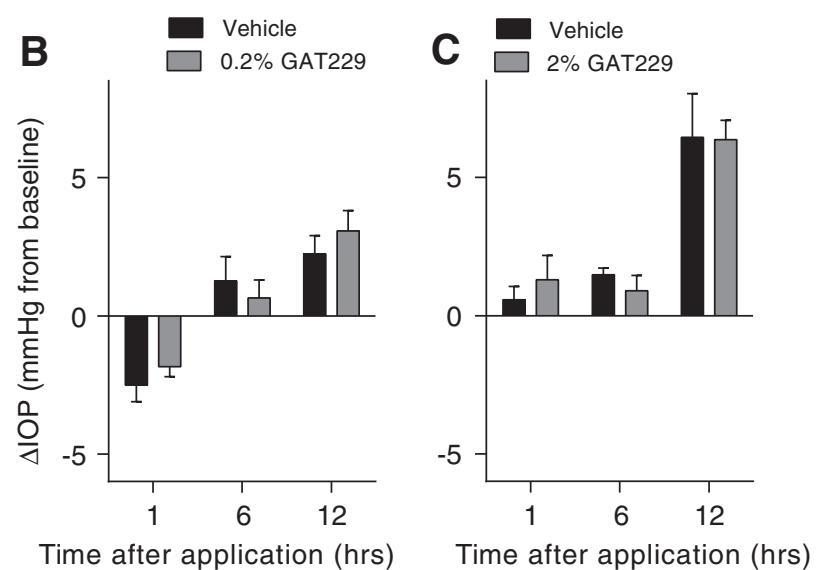

potential $\mathrm{CB}_{1}$ PAM effect on IOP was unknown. Therefore, we investigated changes in pressure from baseline on an extended timeline; 1,6 , and $12 \mathrm{~h}$ after initial administration. As IOP varies diurnally, ${ }^{28,62,63}$ in all mice receiving vehicle, IOP increases were measured at both 6 and $12 \mathrm{~h}$ following baseline measurement $(2.3 \pm 0.5$ and $3.6 \pm 0.5 \mathrm{mmHg}$ from baseline, respectively, $P<0.05)$. Topical administration of the $\mathrm{CB}_{1}$ PAM GAT229 alone at either $0.2 \%$ or $2 \%$ did not appear to have any effect on IOP measured at 1,6 , or $12 \mathrm{~h}$ when compared with eyes receiving vehicle (Fig. 1B, C), consistent with expectations of a $\mathrm{CB}_{1}$ PAM. $^{59}$

To determine whether GAT229 acted as a CB $_{1}$ PAM when administered together with a $\mathrm{CB}_{1}$ orthosteric agonist, a combination of WIN with GAT229 was examined (Fig. 2). The $\mathrm{CB}_{1}$ orthosteric agonist WIN has been reported to lower IOP in mice at $1 \mathrm{~h}$ after topical administration. ${ }^{28}$ Similar to what was previously reported, $1 \mathrm{~h}$ after initial administration, eyes receiving topical $1 \%$ WIN had a greater reduction in IOP than eyes receiving vehicle $(P<0.05,-1.6 \pm 0.7$ and $0.4 \pm 0.6 \mathrm{mmHg}$ from baseline, respectively, $n=9$ ). This ef- fect was no longer present 6 and $12 \mathrm{~h}$ later (Fig. 2A), which is also in alignment with previous reports of the transient time course for reported IOP reduction by $\mathrm{CB}_{1}$ orthosteric agonists. $^{13,14,28}$ However, while topical administration of $0.25 \%$ WIN was subthreshold for lowering IOP at all tested time points $(P>0.05$; Fig. $2 \mathrm{~B})$, the combination of $0.2 \%$ GAT229 and $0.25 \%$ WIN produced a significant reduction in IOP at $6 \mathrm{~h}$, which was sustained at $12 \mathrm{~h}$ after initial topical administration $(P<0.05$, mean difference $3.4 \pm 1.1$ and $3.2 \pm 0.9 \mathrm{mmHg}$, respectively, $n=5$; Fig. 2C), suggesting a PAM-mediated potentiation of the effect of WIN.

Allosteric modulators may display probe specificity, resulting in differences in downstream signaling. ${ }^{67-69}$ To investigate any potential probe-specific effects, GAT229 was also investigated with $\Delta^{9}$-THC, a $\mathrm{CB}_{1}$ partial agonist (Fig. 3). $\Delta^{9}$-THC was chosen due to differences in $\mathrm{CB}_{1}$ binding compared with WIN; ${ }^{70}$ WIN binds deeper in the $\mathrm{CB}_{1}$ orthosteric pocket compared with $\Delta^{9}$-THC. ${ }^{70}$ Topical delivery of $0.5 \%$ or $2 \% \Delta^{9}$-THC failed to significantly lower IOP at 1,2 , or $4 \mathrm{~h}$ after administration compared with
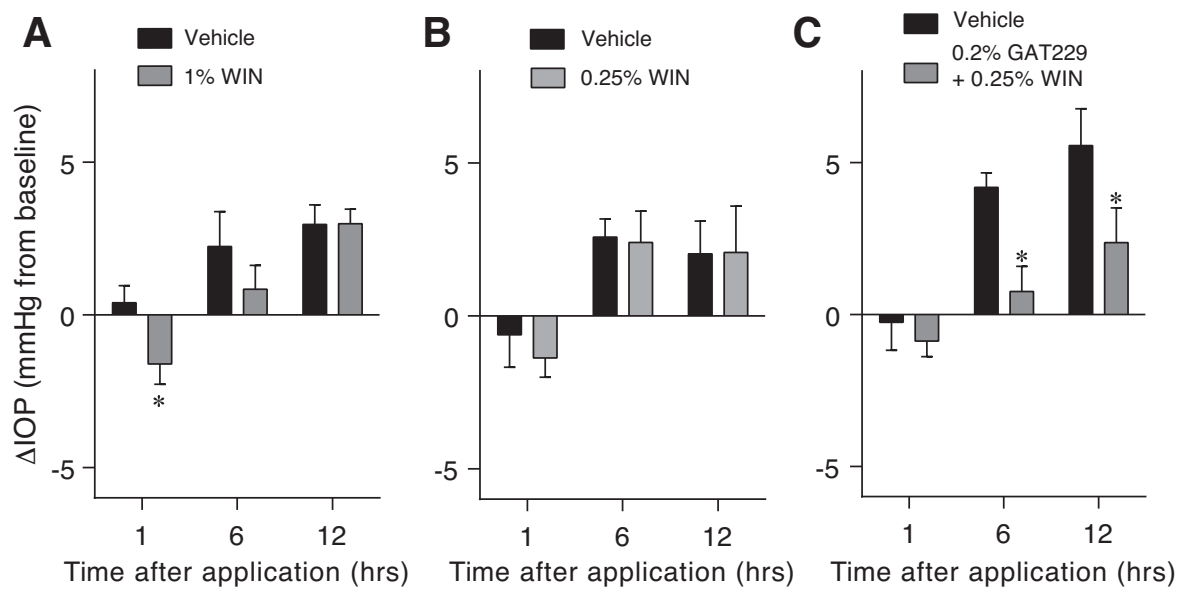

FIG. 2. The IOP-lowering effect of subthreshold WIN is potentiated by the $\mathrm{CB}_{1}$ PAM GAT229 in normotensive $\mathrm{C} 57 \mathrm{~B} 1 / 6 \mathrm{~J}$ mice. (A) One hour after administration, but not at 6 or $12 \mathrm{~h}, 1 \%$ WIN significantly decreased IOP compared with contralateral eye receiving vehicle (Tocrisolve; $-1.6 \pm 0.7$ and $0.4 \pm 0.6 \mathrm{mmHg}$ from baseline respectively, $n=9$ ). However, a lower dose of WIN $(0.25 \%)$ administered alone did not significantly decrease IOP compared to contralateral vehicletreated eyes at any of the time points measured $(n=4)$, and was therefore considered as a subthreshold dose (B). (C) IOP was significantly lower in eyes receiving $0.2 \%$ GAT229 combined with subthreshold WIN $(0.25 \%)$ at 6 and $12 \mathrm{~h}$ after application compared to vehicle $(-0.9 \pm 0.5$ and $-0.3 \pm 0.9,0.8 \pm 0.8$ and $4.2 \pm 0.5$, and $2.4 \pm 1.1$ and $5.6 \pm 1.2 \mathrm{mmHg}$ from baseline, respectively, $n=5$ ). Paired $t$-tests, $* P<0.05 . \mathrm{CB}_{1}$, cannabinoid receptor 1 ; IOP, intraocular pressure; PAM, positive allosteric modulator. 


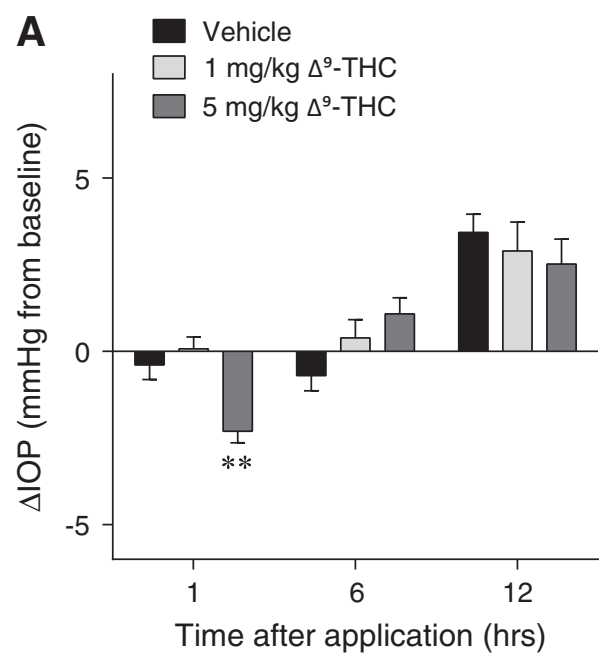

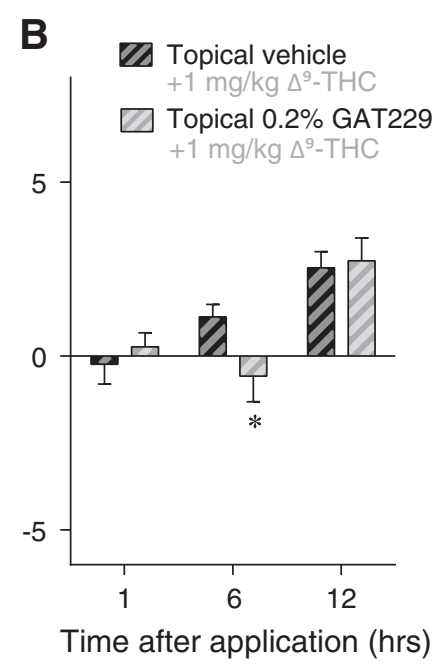

FIG. 3. The IOP-lowering effect of subthreshold $\Delta^{9}$-THC is also potentiated by the PAM GAT229. (A) $5 \mathrm{mg} / \mathrm{kg} \Delta^{9}$-THC caused a significant reduction in IOP $1 \mathrm{~h}$ after i.p. administration compared to mice receiving i.p. vehicle $(P<0.01$, mean difference $1.9 \pm 0.6 \mathrm{mmHg}, n=5$ mice per group). Administration of $1 \mathrm{mg} / \mathrm{kg} \quad \Delta^{9}$-THC $(n=10$ mice) did not lower IOP compared with mice receiving vehicle at 1,6 , or $12 \mathrm{~h}(P>0.05)$. (B) In mice receiving i.p. $1 \mathrm{mg} / \mathrm{kg} \Delta^{9}$-THC, eyes receiving topical $0.2 \%$ GAT22 2 had significantly larger reduction in baseline IOP at $6 \mathrm{~h}$ after administration compared with contralateral eyes receiving topical vehicle $(P<0.05$, mean difference $1.7 \pm 0.6 \mathrm{mmHg}$, $n=9)$. $* P<0.05$, $* * P<0.01$. IOP, intraocular pressure; PAM, positive allosteric modulator; $\Delta^{9}$-THC, $\Delta^{9}$-tetrahydracannabinol. contralateral eyes receiving vehicle $(P>0.05, n=4-9$; data not shown). However, mice receiving i.p. $5 \mathrm{mg} / \mathrm{kg} \Delta^{9}$-THC had a greater reduction in IOP $1 \mathrm{~h}$ after administration compared with a separate group of mice receiving i.p. vehicle $(P<0.01,-2.3 \pm 0.3$ and $-0.4 \pm 0.4 \mathrm{mmHg}$ from baseline, respectively, $n=5$ mice; Fig. $3 \mathrm{~A}$ ). This IOP reduction was not seen at 6 and $12 \mathrm{~h}$ after administration $(P>0.05)$. A lower i.p. dose of $\Delta^{9}$-THC $(1 \mathrm{mg} / \mathrm{kg} ; n=10$ mice $)$ did not alter IOP significantly at 1,6 , or $12 \mathrm{~h}$, compared with mice receiving i.p. vehicle $(P>0.05)$. The potential PAM effect of GAT229, using $\Delta^{9}$-THC as the $\mathrm{CB}_{1}$ orthosteric partial agonist, was explored by administration of i.p. subthreshold $(1 \mathrm{mg} / \mathrm{kg}) \Delta^{9}$-THC, combined with topical $0.2 \%$ GAT229 in one eye and topical vehicle in the fellow eye. At $1 \mathrm{~h}$ following i.p. injection of $1 \mathrm{mg} / \mathrm{kg} \Delta^{9}$-THC, no significant difference between eyes receiving vehicle and those receiving $0.2 \%$ GAT229 was observed. However, at $6 \mathrm{~h}$ there was a significant decrease in IOP from baseline compared with eyes receiving vehicle $(P<0.05,-0.6 \pm 0.7$ and $1.2 \pm 0.4 \mathrm{mmHg}$ from baseline, respectively, $n=9$; Fig. 3B). Unlike the combination with WIN, the PAM effect of GAT229 plus $\Delta^{9}$-THC was not maintained through to $12 \mathrm{~h}(P>0.05)$.

\section{$C B_{1}$ allosteric modulation of IOP in ocular hypertensive mice}

Nee mice have a 1 base pair deletion in $\operatorname{Sh} 3 p x d 2 b$ gene, $^{60}$ causing a loss of function mutation similar to mutations found in the Frank-Ter Haar syndrome, a rare developmental syndrome that frequently involves congenital glaucoma. ${ }^{71-73} \mathrm{Nee}$ mice display closed iridocorneal angles, presumably as a result of improper development. ${ }^{71}$ While at 16 days postnatal (p16), nee mice of both sexes have IOP similar to their wildtype (WT) littermates $(P>0.05 ; 17.6 \pm 1.8 \mathrm{mmHg}, n=6$, and $12.6 \pm 0.4 \mathrm{mmHg}, n=5$, respectively), and nee mice display a significant progressive increase in IOP, which is sustained over their lifetime (Fig. 4). At 28 days postnatal (p28), IOP in nee mice was, on average, $6.8 \pm 2.0 \mathrm{mmHg}$ greater than in WT littermates; and by 37 days postnatal (p37), $11.3 \pm 2.3 \mathrm{mmHg}$. Around 3 months of age $[\sim 100$ days postnatal $(\mathrm{p} \sim 100)]$, this difference remained at $10.6 \pm 2.2 \mathrm{mmHg}$. We used both male and female nee mice aged 2-3 months in this study as a model of spontaneous angle-closure glaucoma to examine the actions of the PAM GAT229 in a model of ocular hypertension.

Unlike in normotensive mice, topical administration of $0.2 \%$ GAT229 alone in nee mice was sufficient to reduce IOP compared with vehicle eyes at both 6 and $12 \mathrm{~h}$ after administration $(n=6, P<0.05$, mean difference $5.8 \pm 2.2$ and $7.7 \pm 3.0 \mathrm{mmHg}$, respectively; Fig. 5A). To investigate whether the route of administration produced a difference in effect, GAT229 was also administered i.p. at $10 \mathrm{mg} / \mathrm{kg}$. While at $6 \mathrm{~h}$ after administration IOP was not significantly different from separate nee mice receiving i.p. vehicle, nee mice had significantly reduced IOP at $12 \mathrm{~h}(n=4$ mice per group, $P<0.01$, mean difference $8.7 \pm 2.5 \mathrm{mmHg}$; Fig. 5B).

Unlike in normotensive mice (Fig. 2A), topically administered $1 \%$ WIN in nee mice failed to produce an IOPlowering effect at 1,6 , or $12 \mathrm{~h}(P>0.05, n=6$; Fig. 6A). Administration of a topical dose of WIN, which was

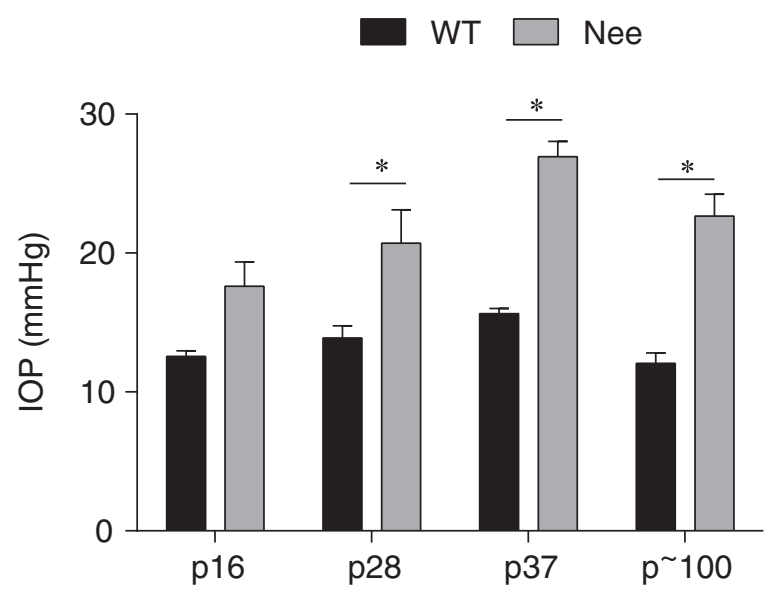

FIG. 4. The nee mouse has ocular hypertension. Nee mice (nose, eyes, ears) have a mutation in $S h 3 p x d 2 b$, a podosome adaptor protein, analogous to humans with Frank-Ter Haar syndrome. $^{60,71}$ Compared with WT littermates, nee mice had significantly elevated IOP by p28 (13.9 \pm 0.9 and $20.7 \pm 2.4 \mathrm{mmHg})$ that persisted until adulthood $(\mathrm{p} \sim 100$; $12.1 \pm 0.8$ and $22.7 \pm 1.6 \mathrm{mmHg})$. $T$-tests, ${ }^{*} P<0.05, n=5-$ 19. IOP, intraocular pressure; nee, nose, eyes, ears; WT, wild type. 
FIG. 5. The $\mathrm{CB}_{1}$ PAM GAT229 reduces IOP alone in ocular hypertensive nee mice. (A) Six and $12 \mathrm{~h}$ following topical administration of $0.2 \%$ GAT229, IOP was significantly less compared to baseline than in eyes receiving vehicle (paired $t$-tests, $n=6$, $-6.9 \pm 2.5$ and $0.2 \pm 2.5$, and $-9.9 \pm 3.1$ and $-2.2 \pm 1.2 \mathrm{mmHg}$ from baseline, respectively). (B) Twelve hours following i.p. administration of $10 \mathrm{mg} / \mathrm{kg}$ GAT229, IOP was significantly reduced compared with nee mice receiving vehicle ( $t$-test, $n=4$ mice per group, $-11.1 \pm 2.2$ and $-2.4 \pm 1.5 \mathrm{mmHg}$ from baseline, respectively). $* P<0.05$, $* * P<0.01 . \mathrm{CB}_{1}$, cannabinoid receptor 1 ; IOP, intraocular pressure; PAM, positive allosteric modulator.
A

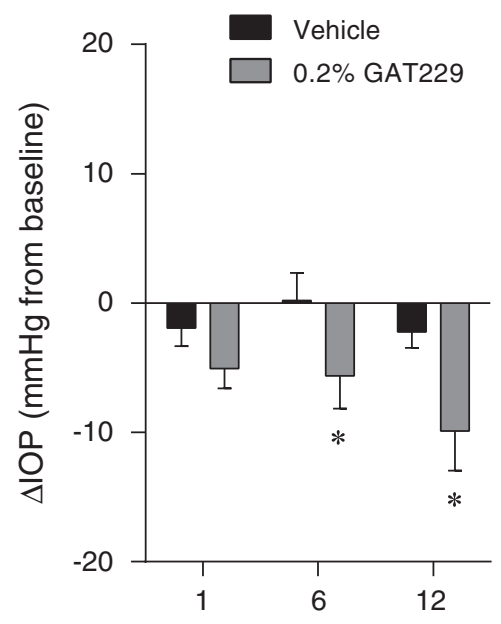

Time after application (hrs)
B

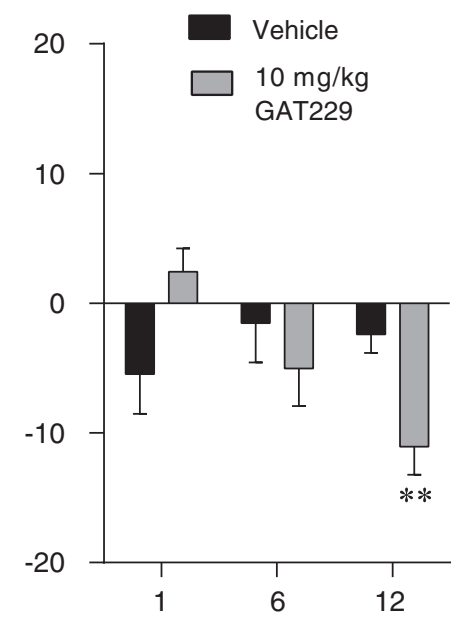

Time after application (hrs) subthreshold in normotensive mice $(0.25 \%$; Fig. $2 \mathrm{~B})$, also did not reduce IOP in nee mice $(P>0.05, n=4$; Fig. 6B). Furthermore, IOP was also not significantly different in eyes receiving subthreshold WIN $(0.25 \%)$ in combination with $0.2 \%$ GAT229 compared with vehicle, 1,6 , or $12 \mathrm{~h}$ after administration $(P>0.05, n=10$, mean difference $0.1 \pm 2.0$, $3.0 \pm 3.0$, and $4.0 \pm 3.3 \mathrm{mmHg}$, respectively; Fig. $6 \mathrm{C})$. This is in contrast to normotensive mice where $0.2 \%$ GAT229+ $0.25 \%$ WIN did produce a significant decrease in IOP $(P<0.05)$ at the latter time points of 6 and $12 \mathrm{~h}$ following administration (Fig. 2C).

\section{Discussion}

$\mathrm{CB}_{1}$ allosteric modulation presents a novel approach to enhance $\mathrm{CB}_{1}$-mediated actions while minimizing the disadvantages of $\mathrm{CB}_{1}$ orthosteric activation. ${ }^{49-53}$ We have demonstrated that the novel $\mathrm{CB}_{1}$ PAM GAT229 not only potentiates the effect of subthreshold WIN and $\Delta^{9}$-THC in normotensive mice but can also change the time to reach peak IOP reduction and/or the duration of the effect in normotensive mice, and in a model of ocular hypertension.

The GAT229-induced increase in the duration of the IOP-lowering effect is in contrast to the relatively shortlived actions of acute orthosteric $\mathrm{CB}_{1}$ activation by can- nabinoids, typically lasting only about $1-2 \mathrm{~h}$ after administration. ${ }^{12-14,16,28,65,66}$ We found that whereas administration of $1 \%$ WIN alone reduced IOP for $\sim 1 \mathrm{~h}$, the combination of subthreshold $(0.25 \%)$ WIN with GAT229 reduced IOP for at least $6 \mathrm{~h}$ in normotensive mice. Duration of action is important when considering use as a clinically relevant therapeutic; drugs with short durations of action require frequent administration, which may lead to issues with patient compliance. ${ }^{74-77}$ Therefore, an increase in duration of effect by $\sim 5 \mathrm{~h}$ (compared with $\mathrm{CB}_{1}$ orthosteric activation alone) would significantly reduce the frequency of administration required to achieve therapeutic efficacy.

The exact mechanisms of $\mathrm{CB}_{1}$-mediated IOP reductions are still obscure, although evidence clearly supports local rather than $\mathrm{CNS}$ or systemic actions. ${ }^{78,79} \mathrm{CB}_{1}$ is expressed by tissues of both the inflow and outflow pathways, and effects of cannabinoids on both aqueous production and outflow facility have been reported. ${ }^{4,5}$ Initially, Colasanti ${ }^{9}$ reported that administration of $\Delta^{9}$-THC delivered via osmotic minipump increased aqueous humor outflow facility in cats. Conversely, Chien et al. ${ }^{14}$ reported that topical administration of WIN reduced aqueous flow in monkeys, without effect on outflow facility, but this decrease could not be completely attributed to a decrease in aqueous humor production. In vitro studies also support multiple sites of
FIG. 6. The IOP-lowering effect of subthreshold WIN is not potentiated by GAT229 in nee mice. Unlike normotensive mice (Fig. 2A), administration of $1 \%$ WIN did not reduce IOP in nee mice $(n=6 ;$ A). Neither subthreshold $(0.25 \%)$ WIN $(n=4 ; \mathbf{B})$ nor the combination of subthreshold WIN and $0.2 \%$ GAT229 had a significant effect on IOP $(n=10$, C). Paired $t$-tests. IOP, intraocular pressure.
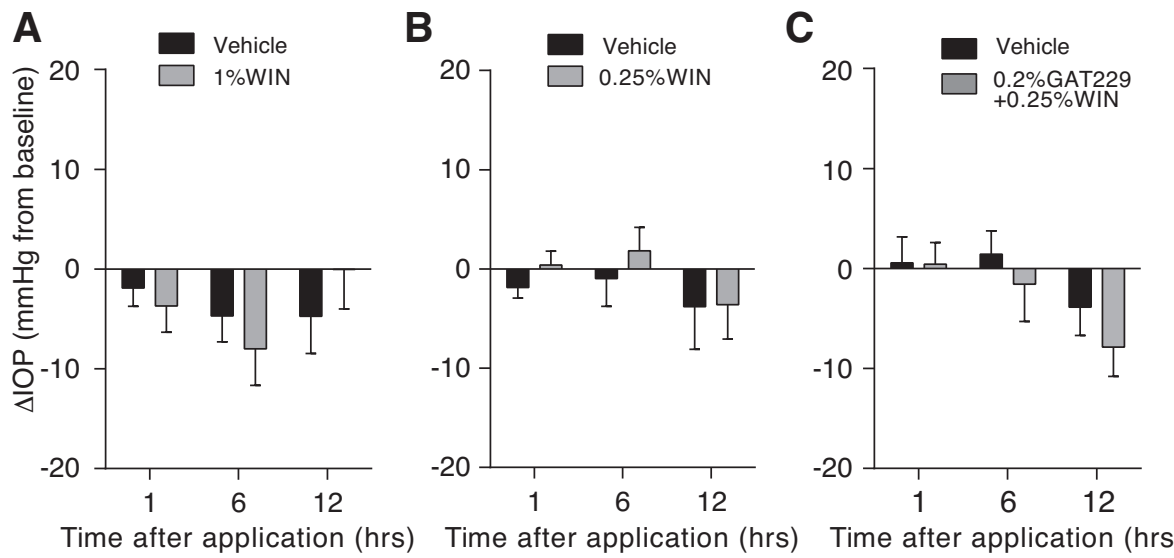
action that may contribute to the ocular hypotensive actions of $\mathrm{CB}_{1}$ ligands. For example, stimulation with cannabinoids produces contractile responses in ciliary muscle, ${ }^{20,27,80}$ relaxation of trabecular meshwork cells, ${ }^{21,22,24}$ and enhanced outflow in perfused anterior segment. ${ }^{23,25,26}$ Furthermore, some $\mathrm{CB}_{1}$ ligands exhibit functional selectivity (bias), due to differential coupling of $G$ proteins. ${ }^{81}$ In cultured human trabecular meshwork cells, WIN was more efficacious than CP55,940, a synthetic cannabinoid, at increasing intracellular calcium. In addition, a stable analogue of the endocannabinoid anandamide (AEA), metAEA, did not produce any measurable increase in intracellular calcium. ${ }^{24}$ This suggests that not only may $\mathrm{CB}_{1}$-mediated decreases in IOP occur via multiple sites of action but that different $\mathrm{CB}_{1}$ ligands may produce disparate effects as well.

How exactly GAT229 extends the $\mathrm{CB}_{1}$-mediated IOPlowering actions is unclear. However, like other PAMs, it is possible that this effect is due to stabilization of $\mathrm{CB}_{1}$ in an intermediate state, extended disassociation time, or by decreasing receptor desensitization. $51,53,56,59$

Selective PAMs cannot activate receptors on their own and are subject to the "ceiling effect" - they require the presence of an orthosteric ligand to exert effects. ${ }^{56}$ Without administration of exogenous cannabinoids, any activity of $\mathrm{CB}_{1}$ PAMs is therefore dependent on the presence of endocannabinoids. This is true of GAT229, which showed no independent activity at $\mathrm{CB}_{1}$ in in vitro studies, but potentiated the effect of several $\mathrm{CB}_{1}$ orthosteric agonists, including the endocannabinoids 2-AG and AEA. ${ }^{59}$ In normotensive mice, the lack of an IOP-lowering effect after administration of GAT229 alone suggests insufficient local endocannabinoids at the site of action (eg, sites of aqueous humor production and/or outflow) to potentiate the effect of GAT229 at $\mathrm{CB}_{1}$. However, the observed IOP-lowering effect of GAT229 alone in nee mice, when either administered topically or i.p., could imply increase endocannabinoids at the site of action compared with normotensive WT mice.

The lack of effect of WIN, alone or combined with GAT229, in nee mice was unexpected. As nee mice represent a model of angle-closure glaucoma, ${ }^{71,72}$ it is possible that IOP modification may not be achievable in models of glaucoma where conventional aqueous humor outflow is restricted. Our results also suggest that the GAT229-potentiated endocannabinoid mechanism of IOP lowering is not the same as the WIN-mediated mechanism.

There is ample evidence of perturbations of the ECS during pathology, including increased endocannabinoids in other models of neurodegeneration such as Alzheimer's disease. $^{6,49,82-84}$ It is unclear if the reasons for this increase in endocannabinoids are a cause, or a result, of pathology. ${ }^{83,84}$ Only 2 studies have attempted to investigate cannabinoid levels in glaucoma. Chen et al. ${ }^{85}$ reported that in human cadaveric eyes, both 2-AG and palmitoylethanolamide (PEA) were decreased in the ciliary body compared with nonglaucomatous eyes (PEA was also decreased in choroid). While AEA levels were reportedly unaffected in the tissues investigated, Nucci et al. ${ }^{42}$ found lowered AEA in the rat retina following an acute model of ocular ischemia/ reperfusion injury consisting of $45 \mathrm{~min}$ of ischemia and $12 \mathrm{~h}$ of reperfusion. However, endocannabinoids are labile; they are degraded rapidly, which poses technical challenges in adequately and consistently capturing true measurements. ${ }^{83}$ Both these existing studies were limited in that they were small sample sizes, postmortem tissue (former) or an acute model (latter), and in both cases only a limited number of lipids were measured at a single time point. Additional investigation of endocannabinoids, their metabolites, and related lipid profiles in chronic glaucoma models, including nee mice, is therefore warranted in future.

The ability to administer GAT229 alone, like other $\mathrm{CB}_{1}$ PAMs, is advantageous in that typical adverse effects associated with systemic orthosteric $\mathrm{CB}_{1}$ activation can be avoided. ${ }^{49-51,53}$ In normal conditions, endocannabinoids are released in a very restricted spatial and temporal pattern. ${ }^{6}$ This is in contrast to systemic administration of orthosteric $\mathrm{CB}_{1}$ agonists, which results in global $\mathrm{CB}_{1}$ activation leading to a vast array of on-target, but undesirable, effects (such as changes in heart rate and psychoactivity). ${ }^{84} \mathrm{CB}_{1}$ PAMs are useful in that if endocannabinoid levels are altered at the site of the pathology (eg, the eye), but not elsewhere (eg, brain regions associated with producing psychotropic effects), PAM administration would cause potentiation of $\mathrm{CB}_{1}$ activity only at the site of pathology, thereby reducing the potential for off-site activation and adverse effects. ${ }^{51,53} \mathrm{We}$ would, therefore, hypothesize that the i.p. administration of GAT229, while still effective at lowering IOP, would not produce tetrad activity (catalepsy, hypothermia, anticonception). In support of this, i.p. administration of a similar $\mathrm{CB}_{1}$ PAM, ZCZ011, alone produced no tetrad activity when given alone, but significantly reduced both mechanical and cold allodynia in a model of chronic constriction nerve injury. ${ }^{86}$ In addition, administration of the parent compound GAT211 (a racemic mixture of GAT229 and GAT228, a partial allosteric agonist) also did not produce tetrad effects when administered alone in WT mice. ${ }^{87}$

Chronic use of high doses of $\mathrm{CB}_{1}$ orthosteric ligands may not be a viable clinically relevant approach as it can lead to not only side effects but also receptor desensitization and loss of effect over time. ${ }^{88,89}$ This is specifically relevant in the development of ocular hypotensive drugs, as many patients require treatment over a number of decades. ${ }^{1,2,90}$ For example, chronic activation of $\mathrm{CB}_{1}$ via monoacylglycerol lipase inhibition (either pharmacologically or genetic) results in not only reduced $\mathrm{CB}_{1}$ expression in neural tissues but also reduced $\mathrm{CB}_{1}$ function. ${ }^{46,91,92}$ While we did not perform chronic administration with GAT229, IgnatowskaJankowska et al. ${ }^{86}$ found that chronic use of their $\mathrm{CB}_{1}$ PAM (ZCZ011) did not result in any loss of effect over time, nor caused a change in endocannabinoid levels. Therefore, GAT229 may be well suited for long-term use.

Given that $\mathrm{CB}_{1}$-negative allosteric modulators behaved quite differently in vivo compared with what was predicted from in vitro, investigation of $\mathrm{CB}_{1}$ PAMs in animals, and particularly in animal models of disease, is essential. ${ }^{93,94}$ In this study, we have demonstrated for the first time the potential of $\mathrm{CB}_{1}$ PAMs to modify IOP, either alone in a model of ocular hypertension or in combination with subthreshold $\mathrm{CB}_{1}$ agonists in normotensive mice. Therefore, administration of $\mathrm{CB}_{1}$ PAMs may provide a novel approach to reduce IOP without the disadvantages associated with orthosteric $\mathrm{CB}_{1}$ activation.

\section{Acknowledgment}

This research was supported by the National Institutes of Health (EY024717). 


\section{Author Disclosure Statement}

M.E.M.K. is the founder and director of Panag Pharma Inc. Panag develops phytotherapeutics for local and regional treatment of pain and inflammation. E.A.C., A.M.S., P.M.K., R.G.P., G.A.T., and W.H.B. have no existing competing financial interests.

\section{References}

1. King, A., Azuara-Blanco, A., and Tuulonen, A. Glaucoma BMJ. 346:f3518, 2013.

2. Heijl, A., Leske, M.C., Bengtsson, B., et al. Reduction of intraocular pressure and glaucoma progression: results from the Early Manifest Glaucoma Trial. Arch. Ophthalmol. 120:1268-1279, 2002.

3. Quigley, H.A. Glaucoma. Lancet. 377:1367-1377, 2011.

4. Cairns, E.A., Baldridge, W.H., and Kelly, M.E. The endocannabinoid system as a therapeutic target in glaucoma. Neural. Plast. 2016:9364091, 2016.

5. Cairns, E.A., Toguri, J.T., Porter, R.F., Szczesniak, A.M., and Kelly, M.E. Seeing over the horizon-targeting the endocannabinoid system for the treatment of ocular disease. J. Basic Clin. Physiol. Pharmacol. 27:253-265, 2016.

6. Ligresti, A., De Petrocellis, L., and Di Marzo, V. From phytocannabinoids to cannabinoid receptors and endocannabinoids: pleiotropic physiological and pathological roles through complex pharmacology. Physiol. Rev. 96:15931659, 2016.

7. Hepler, R.S., and Frank, I.R. Marihuana smoking and intraocular pressure. JAMA. 217:1392, 1971.

8. Green, K., and Pederson, J.E. Effect of 1tetrahydrocannabinol on aqueous dynamics and ciliary body permeability in the rabbit. Exp. Eye Res. 15:499-507, 1973.

9. Colasanti, B.K. A comparison of the ocular and central effects of delta 9-tetrahydrocannabinol and cannabigerol. J. Ocul. Pharmacol. 6:259-269, 1990.

10. Mikawa, Y., Matsuda, S., Kanagawa, T., Tajika, T., Ueda, N., and Mimura, Y. Ocular activity of topically administered anandamide in the rabbit. Jpn. J. Ophthalmol. 41: 217-220, 1997.

11. Beilin, M., Neumann, R., Belkin, M., Green, K., and BarIlan, A. Pharmacology of the intraocular pressure (IOP) lowering effect of systemic dexanabinol (HU-211), a nonpsychotropic cannabinoid. J. Ocul. Pharmacol. Ther. 16: 217-230, 2000.

12. Song, Z.H., and Slowey, C.A. Involvement of cannabinoid receptors in the intraocular pressure-lowering effects of WIN55212-2. J. Pharmacol. Exp. Ther. 292:136-139, 2000.

13. Porcella, A., Maxia, C., Gessa, G.L., and Pani, L. The synthetic cannabinoid WIN55212-2 decreases the intraocular pressure in human glaucoma resistant to conventional therapies. Eur. J. Neurosci. 13:409-412, 2001.

14. Chien, F.Y., Wang, R.F., Mittag, T.W., and Podos, S.M. Effect of WIN 55212-2, a cannabinoid receptor agonist, on aqueous humor dynamics in monkeys. Arch. Ophthalmol. 121:87-90, 2003.

15. Tomida, I., Azuara-Blanco, A., House, H., Flint, M., Pertwee, R.G., and Robson, P.J. Effect of sublingual application of cannabinoids on intraocular pressure: a pilot study. J. Glaucoma. 15:349-353, 2006.

16. Samudre, S.S., Schneider, J.L., Oltmanns, M.H., et al. Comparison of topical and intravenous administration of WIN 55-212-2 in normotensive rabbits. Curr. Eye Res. 33: $857-863,2008$.
17. Caldwell, M.D., Hu, S.S., Viswanathan, S., Bradshaw, H., Kelly, M.E., and Straiker, A. A GPR18-based signalling system regulates IOP in murine eye. Br. J. Pharmacol. 169: 834-843, 2013.

18. Fischer, K.M., Ward, D.A., and Hendrix, D.V. Effects of a topically applied $2 \%$ delta-9-tetrahydrocannabinol ophthalmic solution on intraocular pressure and aqueous humor flow rate in clinically normal dogs. Am. J. Vet. Res. 74: 275-280, 2013.

19. Miller, S., Leishman, E., Hu, S.S., et al. Harnessing the endocannabinoid 2-arachidonoylglycerol to lower intraocular pressure in a murine model. Invest. Ophthalmol. Vis. Sci. 57:3287-3296, 2016.

20. Lograno, M.D., and Romano, M.R. Cannabinoid agonists induce contractile responses through Gi/o-dependent activation of phospholipase $\mathrm{C}$ in the bovine ciliary muscle. Eur. J. Pharmacol. 494:55-62, 2004.

21. Stumpff, F., Boxberger, M., Krauss, A., et al. Stimulation of cannabinoid (CB1) and prostanoid (EP2) receptors opens $\mathrm{BKCa}$ channels and relaxes ocular trabecular meshwork. Exp. Eye Res. 80:697-708, 2005.

22. Kumar, A., and Song, Z.H. CB1 cannabinoid receptormediated changes of trabecular meshwork cellular properties. Mol. Vis. 12:290-297, 2006.

23. Njie, Y.F., Kumar, A., Qiao, Z., Zhong, L., and Song, Z.H. Noladin ether acts on trabecular meshwork cannabinoid (CB1) receptors to enhance aqueous humor outflow facility. Invest. Ophthalmol. Vis. Sci. 47:1999-2005, 2006.

24. McIntosh, B.T., Hudson, B., Yegorova, S., Jollimore, C.A., and Kelly, M.E. Agonist-dependent cannabinoid receptor signalling in human trabecular meshwork cells. Br. J. Pharmacol. 152:1111-1120, 2007.

25. Njie, Y.F., He, F., Qiao, Z., and Song, Z.H. Aqueous humor outflow effects of 2-arachidonylglycerol. Exp. Eye Res. 87: 106-114, 2008.

26. Njie, Y.F., Qiao, Z., Xiao, Z., Wang, W., and Song, Z.H. $\mathrm{N}$-arachidonylethanolamide-induced increase in aqueous humor outflow facility. Invest. Ophthalmol. Vis. Sci. 49:45284534, 2008.

27. Romano, M.R., and Lograno, M.D. Signaling cross-talk between cannabinoid and muscarinic systems actives Rhokinase and increases the contractile responses of the bovine ciliary muscle. Eur. J. Pharmacol. 702:174-179, 2013.

28. Hudson, B.D., Beazley, M., Szczesniak, A.M., Straiker, A., and Kelly, M.E. Indirect sympatholytic actions at betaadrenoceptors account for the ocular hypotensive actions of cannabinoid receptor agonists. J. Pharmacol. Exp. Ther. 339: 757-767, 2011.

29. Almasieh, M., Wilson, A.M., Morquette, B., Cueva Vargas, J.L., and Di Polo, A. The molecular basis of retinal ganglion cell death in glaucoma. Prog. Retin..Eye Res. 31:152$181,2012$.

30. Nickells, R.W., Howell, G.R., Soto, I., and John, S.W. Under pressure: cellular and molecular responses during glaucoma, a common neurodegeneration with axonopathy. Annu. Rev. Neurosci. 35:153-179, 2012.

31. Rieck, J. The pathogenesis of glaucoma in the interplay with the immune system. Invest. Ophthalmol. Vis. Sci. 54: 2393-2409, 2013.

32. Vohra, R., Tsai, J.C., and Kolko, M. The role of inflammation in the pathogenesis of glaucoma. Surv. Ophthalmol. 58:311-320, 2013.

33. Schmidl, D., Schmetterer, L., Garhofer, G., and PopaCherecheanu, A. Pharmacotherapy of glaucoma. J. Ocul. Pharmacol. Ther. 31:63-77, 2015. 
34. Nucci, C., Russo, R., Martucci, A., et al. New strategies for neuroprotection in glaucoma, a disease that affects the central nervous system. Eur. J. Pharmacol. 787:119-126, 2016.

35. Zhang, K., Zhang, L., and Weinreb, R.N. Ophthalmic drug discovery: novel targets and mechanisms for retinal diseases and glaucoma. Nat. Rev. Drug. Discov. 11:541-559, 2012.

36. Liu, Y., and Pang, I.H. Challenges in the development of glaucoma neuroprotection therapy. Cell Tissue Res. 353: 253-260, 2013.

37. Sena, D.F., and Lindsley, K. Neuroprotection for treatment of glaucoma in adults. Cochrane Database Syst. Rev. 2: CD006539, 2013.

38. Tamm, E.R., Schmetterer, L., and Grehn, F. Status and perspectives of neuroprotective therapies in glaucoma: the European Glaucoma Society White Paper. Cell Tissue Res. 353:347-354, 2013.

39. Weinreb, R.N., Aung, T., and Medeiros, F.A. The pathophysiology and treatment of glaucoma: a review. JAMA. 311:1901-1911, 2014.

40. El-Remessy, A.B., Khalil, I.E., Matragoon, S., et al. Neuroprotective effect of (-)Delta9-tetrahydrocannabinol and cannabidiol in N-methyl-D-aspartate-induced retinal neurotoxicity: involvement of peroxynitrite. Am. J. Pathol. 163: 1997-2008, 2003.

41. Crandall, J., Matragoon, S., Khalifa, Y.M., et al. Neuroprotective and intraocular pressure-lowering effects of (-) Delta9-tetrahydrocannabinol in a rat model of glaucoma. Ophthalmic. Res. 39:69-75, 2007.

42. Nucci, C., Gasperi, V., Tartaglione, R., et al. Involvement of the endocannabinoid system in retinal damage after high intraocular pressure-induced ischemia in rats. Invest. Ophthalmol. Vis. Sci. 48:2997-3004, 2007.

43. Pinar-Sueiro, S., Zorrilla Hurtado, J.A., Veiga-Crespo, P., Sharma, S.C., and Vecino, E. Neuroprotective effects of topical CB1 agonist WIN 55212-2 on retinal ganglion cells after acute rise in intraocular pressure induced ischemia in rat. Exp. Eye Res. 110:55-58, 2013.

44. Slusar, J.E., Cairns, E.A., Szczesniak, A.M., Bradshaw, H.B., Di Polo, A., and Kelly, M.E. The fatty acid amide hydrolase inhibitor, URB597, promotes retinal ganglion cell neuroprotection in a rat model of optic nerve axotomy. Neuropharmacology. 72C:116-125, 2013.

45. Yazulla, S. Endocannabinoids in the retina: from marijuana to neuroprotection. Prog. Retin. Eye Res. 27:501-526, 2008.

46. Ghosh, S., Wise, L.E., Chen, Y., et al. The monoacylglycerol lipase inhibitor JZL184 suppresses inflammatory pain in the mouse carrageenan model. Life Sci. 92: 498-505, 2013.

47. Flom, M.C., Adams, A.J., and Jones, R.T. Marijuana smoking and reduced pressure in human eyes: drug action or epiphenomenon? Invest. Ophthalmol. 14:52-55, 1975.

48. Green, K. Marijuana smoking vs cannabinoids for glaucoma therapy. Arch. Ophthalmol. 116:1433-1437, 1998.

49. Pertwee, R.G. The therapeutic potential of drugs that target cannabinoid receptors or modulate the tissue levels or actions of endocannabinoids. AAPS J. 7:E625-E654, 2005.

50. Ross, R.A. Allosterism and cannabinoid $\mathrm{CB}_{1}$ receptors: the shape of things to come. Trends Pharmacol. Sci. 28:567572, 2007.

51. Janero, D.R., and Thakur, G.A. Leveraging allostery to improve G protein-coupled receptor (GPCR)-directed therapeutics: cannabinoid receptor 1 as discovery target. Expert Opin. Drug Discov. 11:1223-1237, 2016.
52. Morales, P., Goya, P., Jagerovic, N., and HernandezFolgado, L. Allosteric modulators of the CB1 cannabinoid receptor: a structural update review. Cannabis Cannabinoid Res 1:22-30, 2016.

53. Nguyen, T., Li, J.X., Thomas, B.F., Wiley, J.L., Kenakin, T.P., and Zhang, Y. Allosteric modulation: an alternate approach targeting the cannabinoid CB1 receptor. Med. Res. Rev. 37:441-474, 2017.

54. Price, M.R., Baillie, G.L., Thomas, A., et al. Allosteric modulation of the cannabinoid CB1 receptor. Mol. Pharmacol. 68:1484-1495, 2005.

55. Khurana, L., Fu, B.Q., Duddupudi, A.L., et al. Pyrimidinyl biphenylureas: identification of new lead compounds as allosteric modulators of the cannabinoid receptor CB1. J. Med. Chem. 60:1089-1104, 2017.

56. Kenakin, T. Theoretical aspects of GPCR-ligand complex pharmacology. Chem. Rev. 117:4-20, 2017.

57. Volkow, N.D., Hampson, A.J., and Baler, R.D. Don't worry, be happy: endocannabinoids and cannabis at the intersection of stress and eward. Annu. Rev. Pharmacol. Toxicol. 57:285-308, 2017.

58. Conn, P.J., Christopoulos, A., and Lindsley, C.W. Allosteric modulators of GPCRs: a novel approach for the treatment of CNS disorders. Nat. Rev. Drug Discov. 8:4154, 2009.

59. Laprairie, R.B., Kulkarni, P.M., Deschamps, J.R., et al. Enantio-specific allosteric modulation of cannabinoid 1 receptor. ACS Chem. Neurosci. 8:1188-1203, 2017.

60. Mao, M., Thedens, D.R., Chang, B., et al. The podosomaladaptor protein SH3PXD2B is essential for normal postnatal development. Mamm. Genome. 20:462-475, 2009.

61. Kulkarni, P.M., Ranade, A., Garai, S., and Thakur, G.A. Microwave-accelerated conjugate addition of 2-arylindoles to substituted $\beta$-nitrostyrenes in the presence of ammonium trifluoroacetate: an efficient approach for the synthesis of a novel class of CB1 cannabinoid receptor allosteric modulators. J. Heterocyclic Chem. 54:2079-2084, 2017.

62. Konstas, A.G., Mantziris, D.A., Cate, E.A., and Stewart, W.C. Effect of timolol on the diurnal intraocular pressure in exfoliation and primary open-angle glaucoma. Arch. Ophthalmol. 115:975-979, 1997.

63. Aihara, M., Lindsey, J.D., and Weinreb, R.N. Twenty-fourhour pattern of mouse intraocular pressure. Exp. Eye Res. 77:681-686, 2003.

64. Laine, K., Järvinen, K., Pate, D.W., Urtti, A., and Järvinen, T. Effect of the enzyme inhibitor, phenylmethylsulfonyl fluoride, on the IOP profiles of topical anandamides. Invest. Ophthalmol. Vis. Sci. 43:393-397, 2002.

65. Szczesniak, A.M., Kelly, M.E., Whynot, S., Shek, P.N., and Hung, O. Ocular hypotensive effects of an intratracheally delivered liposomal delta9-tetrahydrocannabinol preparation in rats. J. Ocul. Pharmacol. Ther. 22:160-167, 2006.

66. Oltmanns, M.H., Samudre, S.S., Castillo, I.G., et al. Topical WIN55212-2 alleviates intraocular hypertension in rats through a CB1 receptor mediated mechanism of action. $J$. Ocul. Pharmacol. Ther. 24:104-115, 2008.

67. Baillie, G.L., Horswill, J.G., Anavi-Goffer, S., et al. $\mathrm{CB}_{1}$ receptor allosteric modulators display both agonist and signaling pathway specificity. Mol. Pharmacol. 83:322-338, 2013.

68. Keov, P., Sexton, P.M., and Christopoulos, A. Allosteric modulation of $\mathrm{G}$ protein-coupled receptors: a pharmacological perspective. Neuropharmacology. 60:24-35, 2011.

69. Wootten, D., Christopoulos, A., and Sexton, P.M. Emerging paradigms in GPCR allostery: implications for drug discovery. Nat. Rev. Drug. Discov. 12:630-644, 2013. 
70. Hua, T., Vemuri, K., Pu, M., et al. Crystal structure of the human cannabinoid receptor CB1. Cell. 167:750-762.e14, 2016.

71. Mao, M., Hedberg-Buenz, A., Koehn, D., John, S.W., and Anderson, M.G. Anterior segment dysgenesis and earlyonset glaucoma in nee mice with mutation of Sh3pxd2b. Invest. Ophthalmol. Vis. Sci. 52:2679-2688, 2011.

72. Iqbal, Z., Cejudo-Martin, P., de Brouwer, A., et al. Disruption of the podosome adaptor protein TKS4 (SH3PXD2B) causes the skeletal dysplasia, eye, and cardiac abnormalities of Frank-Ter Haar syndrome. Am. J. Hum. Genet. 86:254-261, 2010.

73. Aktas, Z., Karaca, E.E., Dogan, N., et al. Congenital glaucoma as an ophthalmic manifestation of Frank-Ter Haar syndrome. Int. Ophthalmol. 34:351-354, 2014.

74. Buchan, J.C., Siddiqui, S., and Gilmour, D. Simplification of eye drop regimes helps reduce involuntary noncompliance with glaucoma treatment. Graefe's Arch. Clin. Exp. Ophthalmol. 245:327-328, 2007.

75. Hermann, M.M., Papaconstantinou, D., Muether, P.S., Georgopoulos, G., and Diestelhorst, M. Adherence with brimonidine in patients with glaucoma aware and not aware of electronic monitoring. Acta Ophthalmol. 89:e300-e305, 2011.

76. Hermann, M.M., Bron, A.M., Creuzot-Garcher, C.P., and Diestelhorst, M. Measurement of adherence to brimonidine therapy for glaucoma using electronic monitoring. $J$. Glaucoma. 20:502-508, 2011.

77. Reardon, G., Kotak, S., and Schwartz, G.F. Objective assessment of compliance and persistence among patients treated for glaucoma and ocular hypertension: a systematic review. Patient Prefer. Adherence. 5:441-463, 2011.

78. Liu, J.H., and Dacus, A.C. Central nervous system and peripheral mechanisms in ocular hypotensive effect of cannabinoids. Arch. Ophthalmol. 105:245-248, 1987.

79. Pate, D.W., Jarvinen, K., Urtti, A., Mahadevan, V., and Jarvinen, T. Effect of the CB1 receptor antagonist, SR141716A, on cannabinoid-induced ocular hypotension in normotensive rabbits. Life Sci. 63:2181-2188, 1998.

80. Romano, M.R., and Lograno, M.D. Evidence for the involvement of cannabinoid $\mathrm{CB} 1$ receptors in the bimatoprostinduced contractions on the human isolated ciliary muscle. Invest. Ophthalmol. Vis. Sci. 48:3677-3682, 2007.

81. Laprairie, R.B., Bagher, A.M., and Denovan-Wright, E.M. Cannabinoid receptor ligand bias: implications in the central nervous system. Curr. Opin. Pharmacol. 32:32-43, 2017.

82. Di Marzo, V., and Petrosino, S. Endocannabinoids and the regulation of their levels in health and disease. Curr. Opin. Lipidol. 18:129-140, 2007.

83. Di Marzo, V. Targeting the endocannabinoid system: to enhance or reduce? Nat. Rev. Drug Discov. 7:438-455, 2008.

84. Pacher, P., and Kunos, G. Modulating the endocannabinoid system in human health and disease-successes and failures. FEBS J. 280:1918-1943, 2013.
85. Chen, J., Matias, I., Dinh, T., et al. Finding of endocannabinoids in human eye tissues: implications for glaucoma. Biochem. Biophys. Res. Commun. 330:1062-1067, 2005.

86. Ignatowska-Jankowska, B.M., Baillie, G.L., Kinsey, S., et al. A cannabinoid CB1 receptor-positive allosteric modulator reduces neuropathic pain in the mouse with no psychoactive effects. Neuropsychopharmacology. 40:29482959, 2015.

87. Slivicki, R.A., Kulkarni, P.M., Pertwee, R.G., et al. Positive allosteric modulation of CB1 suppresses pathological pain without producing tolerance or dependence. Biol. Psychiatry. 2017 [Epub ahead of print]; DOI: 10.1016/j.biopsych.2017 .06 .032 .

88. González, S., Cebeira, M., and Fernández-Ruiz, J. Cannabinoid tolerance and dependence: a review of studies in laboratory animals. Pharmacol. Biochem. Behav. 81:300318, 2005.

89. Lichtman, A.H., and Martin, B.R. Cannabinoid tolerance and dependence. Handb. Exp. Pharmacol. (168):691-717, 2005.

90. Lee, A.J., and Goldberg, I. Emerging drugs for ocular hypertension. Expert Opin. Emerg. Drugs. 16:137-161, 2011.

91. Schlosburg, J.E., Blankman, J.L., Long, J.Z., et al. Chronic monoacylglycerol lipase blockade causes functional antagonism of the endocannabinoid system. Nat. Neurosci. 13:1113-1119, 2010.

92. Schlosburg, J.E., Kinsey, S.G., Ignatowska-Jankowska, B., et al. Prolonged monoacylglycerol lipase blockade causes equivalent cannabinoid receptor type 1 receptor-mediated adaptations in fatty acid amide hydrolase wild-type and knockout mice. J. Pharmacol. Exp. Ther. 350:196-204, 2014.

93. Ding, Y., Qiu, Y., Jing, L., Thorn, D.A., Zhang, Y., and Li, J.X. Behavioral effects of the cannabinoid CB1 receptor allosteric modulator ORG27569 in rats. Pharmacol. Res. Perspect. 2:e00069, 2014.

94. Gamage, T.F., Ignatowska-Jankowska, B.M., Wiley, J.L., et al. In-vivo pharmacological evaluation of the CB1receptor allosteric modulator Org-27569. Behav. Pharmacol. 25:182-185, 2014.

Received: March 17, 2017 Accepted: June 13, 2017

Address correspondence to: Dr. Melanie E.M. Kelly Department of Pharmacology Dalhousie University 5850 College Street Halifax, Nova Scotia, B3H $4 R 2$ Canada

E-mail: melanie.kelly@dal.ca 